Santa Clara University

Scholar Commons

Electrical Engineering

School of Engineering

$12-25-2006$

\title{
Interface Characteristics of Vertically Aligned Carbon Nanofibers for Interconnect Applications
}

Yusuke Ominami

Quoc Ngo

Makoto Suzuki

Alexander J.Austin

Cary Y. Yang

Santa Clara University, cyang@scu.edu

See next page for additional authors

Follow this and additional works at: https://scholarcommons.scu.edu/elec

\section{Recommended Citation}

Y. Ominami, Q. Ngo, M. Suzuki, A.J. Austin, C.Y. Yang, A.M. Cassell, and J. Li, "Interface Characteristics of vertically Aligned Carbon Nanofibers for Interconnect Applications," Applied Physics Letters 89, 263114 (3 pp) (2006). https://doi.org/10.1063/1.2423241

Copyright (C) 2006 American Institute of Physics Publishing. Reprinted with permission.

This Article is brought to you for free and open access by the School of Engineering at Scholar Commons. It has been accepted for inclusion in Electrical Engineering by an authorized administrator of Scholar Commons. For more information, please contact rscroggin@scu.edu. 
Authors

Yusuke Ominami, Quoc Ngo, Makoto Suzuki, Alexander J. Austin, Cary Y. Yang, Alan M. Cassell, and Jun Li 


\title{
Interface characteristics of vertically aligned carbon nanofibers for interconnect applications
}

\author{
Yusuke Ominami, Quoc Ngo, Makoto Suzuki, Alexander J. Austin, and Cary Y. Yang ${ }^{\text {a) }}$ \\ Center for Nanostructures, Santa Clara University, 500 El Camino Real, Santa Clara, \\ California 95053
}

Alan M. Cassell and Jun Li

NASA Ames Research Center, Center for Nanotechnology, Moffett Field, California 94035

(Received 9 June 2006; accepted 17 November 2006; published online 29 December 2006)

\begin{abstract}
The authors characterize the detailed interface structure of Ni-catalyzed vertically aligned carbon nanofibers (CNFs) prepared by plasma-enhanced chemical vapor deposition for interconnect applications. Stacked graphitic layers and cup-shape structures of CNFs around the interface region have been observed using high-resolution scanning transmission electron microscopy. The interaction between the Ni catalyst and Ti layer dramatically affects the CNF structure during initial growth. The effect of interface nanostructures on contact resistance is also discussed. () 2006 American Institute of Physics. [DOI: 10.1063/1.2423241]
\end{abstract}

Since plasma-enhanced chemical vapor deposition (PECVD) was first shown to be capable of growing carbon nanotubes (CNTs) with uniform directional control, ${ }^{1,2}$ vertically aligned CNTs and carbon nanofibers (CNFs) grown by PECVD have been reported for various applications. ${ }^{3-5}$ For future integrated devices, a "bottom-up approach" for electrical interconnects using CNF has been proposed. ${ }^{6,7}$ For implementation of CNFs in electrical interconnect applications, the resistance of CNFs must be minimized. Because the interface structure between $\mathrm{CNF}$ and the metal layer affects electronic transport properties in the form of contact resistance, it is important to reveal how CNFs with minimal contact resistance on a metal layer can be fabricated. The initial growth mechanism of vertically aligned CNFs on a $\mathrm{Si}$ substrate was first demonstrated by Wen et al. ${ }^{8}$ and later by Cui et al. ${ }^{9}$ Initially, the Ni catalyst particle separates from the Si substrate, changing its shape from hemispherical to pear shaped. Concurrently, graphitic layers are created depending on the exact geometry of the Ni particle on the Si substrate. This phenomenon implies that the interface structure of the CNF strongly depends on the shape of the Ni particle during the initial reaction. ${ }^{8}$ However, studies thus far using highresolution transmission electron microscopy (TEM) or scanning TEM (STEM) have not led to a satisfactory understanding of the detailed behavior of the Ni catalyst on the metal underlayer during initial growth. Moreover, it would be of interest to understand how the graphitic planes of CNFs are created as the catalyst particle changes its shape and affects the contact resistance. In this letter, the behavior of the $\mathrm{Ni}$ catalyst on Ti during the initial growth stages is illustrated using high-resolution STEM. The effect of interface nanostructures on contact resistance is also discussed.

In order to prepare the cross-sectional CNF sample for characterization of the interface structure between CNF and $\mathrm{Ti}$ underlayer, the following procedure is performed. First, a $30 \mathrm{~nm}$ Ti layer and a $35 \mathrm{~nm} \mathrm{Ni}$ catalyst layer are deposited on a $\mathrm{Si}$ wafer using electron beam evaporation. The Ti layer serves two roles here, e.g., as a barrier layer to prevent $\mathrm{Ni}$

\footnotetext{
${ }^{a}$ Author to whom correspondence should be addressed; electronic mail: cyang@scu.edu
}

diffusion into $\mathrm{Si}$ to form nickel silicides and as the bottom electrical connections to the CNFs. Subsequently, a narrow strip approximately $80 \mathrm{~nm}$ in width is fabricated by locally milling the $\mathrm{Ni}, \mathrm{Ti}$, and $\mathrm{Si}$ layers using focused ion beam (FIB: Hitachi FB-2100). Finally, CNFs are selectively grown on the narrow strip using PECVD. The length of CNFs is controlled by the reaction time. The details of this sample preparation technique have been reported by our group. ${ }^{10}$ With this sample preparation technique, the number of distinctly observable interfacial structures is much higher than that prepared by conventional sample preparation, ${ }^{9}$ and the CNFs grown on the narrow strip are not subjected to any damage associated with ion milling. Approximately 100 CNF structures on the narrow strip are examined using highresolution STEM (Hitachi HD-2300).

CNFs with lengths of approximately $50 \mathrm{~nm}$ are shown in Fig. 1(a). In $80 \%-90 \%$ of the structures observed with STEM, the stacked graphitic layers are parallel to the metal layer underneath the $\mathrm{Ni}$ particle [Figs. 1(b) and 1(c)] but nearly perpendicular to the CNF axis. Graphitic layers forming a smaller angle with the CNF axis are observed in the remaining 10\%-20\%, as shown in Figs. 1(d) and 1(e). This structure is likely a result of strong bonding between the $\mathrm{Ni}$ particle and Ti layer, making it difficult for the Ni particle to separate from the substrate during initial growth. Accordingly, graphitic layers with small cone angles are created near the interface region. At the interface between $\mathrm{Ni}, \mathrm{Ti}$, and CNF [Fig. 1(f)], lattice spacings of 0.20 and $0.25 \mathrm{~nm}$ are observed in the Ni particle and Ti layer, respectively. While $0.20 \mathrm{~nm}$ corresponds to $\mathrm{Ni}$ (111) plane, $0.25 \mathrm{~nm}$ does not match any low-index Ti interplanar spacing. From the result of energy-dispersive x-ray spectroscopy (EDX), the presence of carbon in the Ti layer is observed, as shown in Fig. 1(g). Therefore, the observed structure in the Ti layer is likely TiC (111) with a spacing of $0.25 \mathrm{~nm}$. The misorientation between $\mathrm{Ni}(111)$ and $\mathrm{TiC}$ (111) leads to bonding between $\mathrm{Ni}$ and $\mathrm{Ti}$ as previously reported. ${ }^{11}$ This finding is consistent with interface characteristics between single-wall carbon nanotube and TiC reported previously. ${ }^{12}$

The interfacial structure of a CNF array of a few micrometers in length is shown in Fig. 2(a). In this image, the 


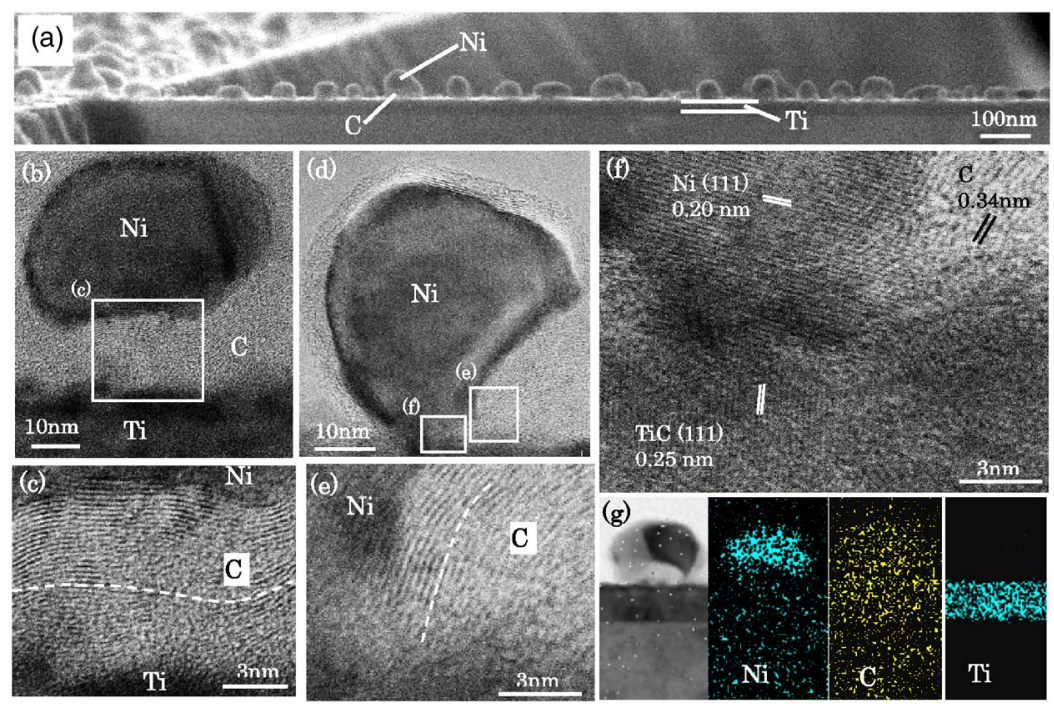

FIG. 1. (Color online) Interface region of $50 \mathrm{~nm}$ long CNFs. (a) SEM image of CNFs on the narrow strip formed by FIB. (b) and (c): STEM images of stacked graphitic layers between $\mathrm{Ni}$ and Ti layer, accounting for $80 \%-90 \%$ of CNFs. (d) and (e): CNF exhibiting low cone angles, accounting for $10 \%-20 \%$ of CNFs. (f) Interface region among $\mathrm{Ni}, \mathrm{TiC}$, and $\mathrm{C}$. In (c) and (e), the dashed lines indicate the orientation of graphitic layers. (g) EDX elemental analysis of the interface region, showing cross-sectional image, $\mathrm{Ni}, \mathrm{C}$, and Ti maps.

sample is tilted, resulting in a $30^{\circ}$ angle between the beam and the substrate normal. All CNFs have a familiar cupshape structure in the interior and catalyst tip as shown in Fig. 2(b), similar to previously reported results. ${ }^{13}$ As in the case of CNFs shown in Fig. 1(c), many CNFs (approximately $90 \%$ ) grown on the narrow strip have graphitic layers parallel to the substrate, as shown in Fig. 2(c). In about $10 \%$ of the CNFs, another interface structure is observed, as shown in Figs. 2(d) and 2(e). This resembles the cup-shape structure observed around the midsection of the CNF. The angles between the basal planes of each graphitic layer and the CNF axis are smaller than those in Fig. 2(c).

Our results show that the interaction between the catalyst and the metal underlayer dramatically affects the CNF struc-

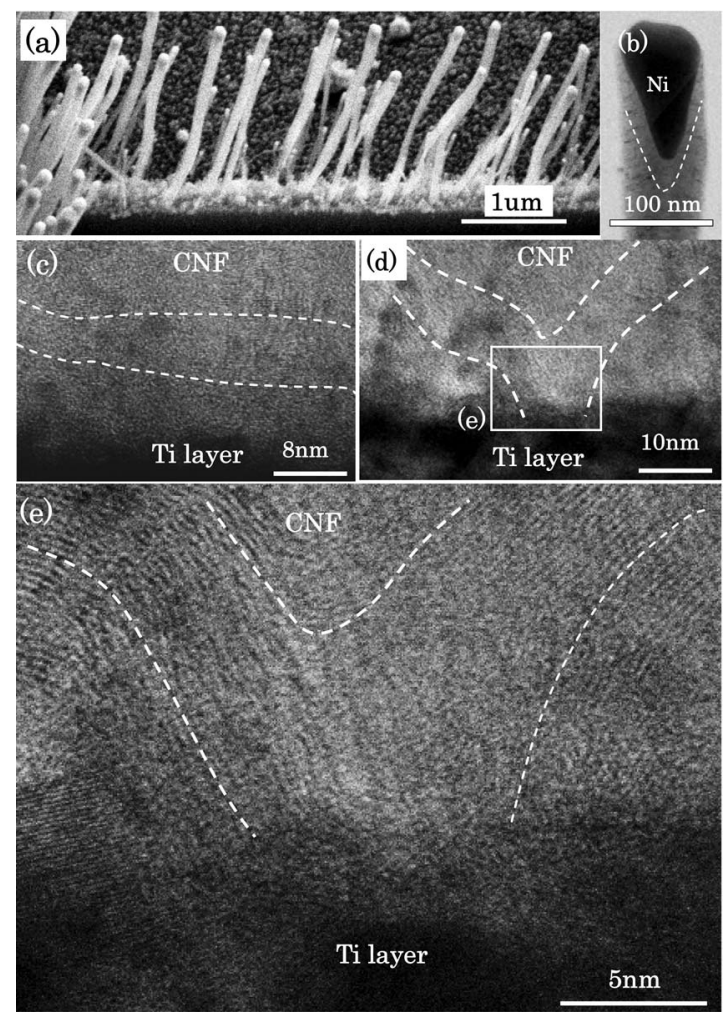

FIG. 2. Interface region of $1-3 \mu \mathrm{m}$ long CNFs. (a) SEM image of CNFs on the $100 \mathrm{~nm}$ wide strip (tilted $30^{\circ}$ with respect to the substrate). (b) CNF diameter is approximately $80 \mathrm{~nm}$. In (b)-(e), the dashed lines indicate the orientation of graphitic layers. ture near the interface region. The reason why various kinds of interface structures are obtained between CNF and Ti underlayer is possibly related to the fact that the sputtered $\mathrm{Ti}$ layer consists of microcrystalline grains as shown in Figs. 3(a) and 3(b). In Fig. 3(c), a grain of TiC that can lead to the strong bond between $\mathrm{Ti}$ and $\mathrm{Ni}$ is clearly observed in the region where the Ni particle and $\mathrm{Ti}$ layer are in close proximity (darker area), but not found in the rest of the interface. Based on this observation, the growth mechanism of the different structure is explained as follows. A different lattice direction of Ti creates a different interface structure between $\mathrm{Ti}$ and Ni. During initial growth of the CNF, the variety of the interface structure also affects the probability of TiC creation and/or the transformation of the thin Ni layer into par-
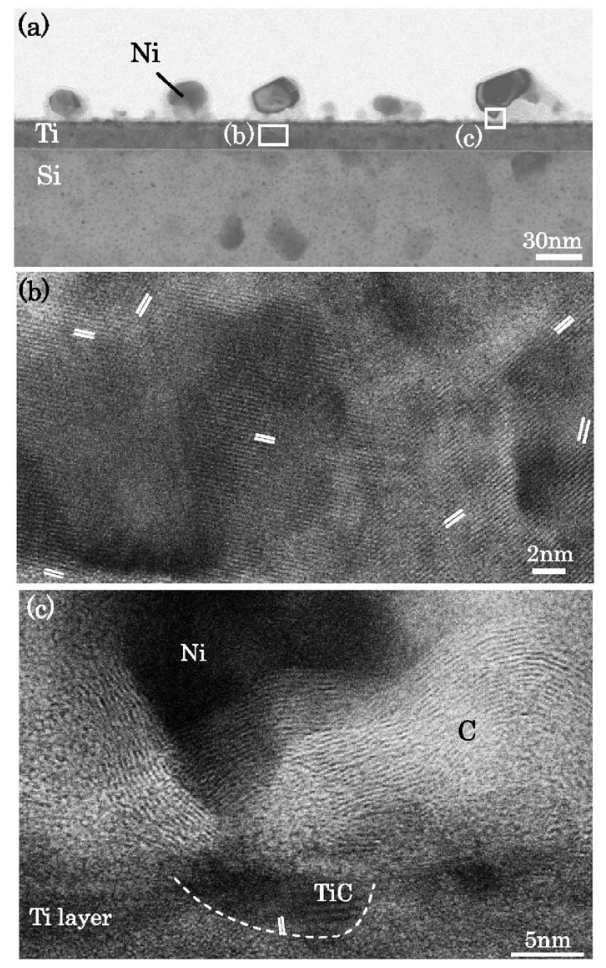

FIG. 3. (a) STEM images of interface region of $50 \mathrm{~nm}$ long CNFs grown on Ti underlayer and Si substrate. (b) High-resolution STEM imaging of microcrystalline Ti underlayer. Some lattice directions are observed. (c) Interface region among $\mathrm{Ni}, \mathrm{Ti}, \mathrm{TiC}$, and $\mathrm{C}$, showing that $\mathrm{TiC}$ is formed only in close proximity of $\mathrm{Ni}$ and $\mathrm{Ti}$. 
ticles. The occurrence of these events, strong Ti-Ni bonding, $\mathrm{TiC}$ formation, and $\mathrm{Ni}$ particle formation, is necessary to result in CNFs grown with structures shown in Figs. 2(d) and 2(e). Thus only a small fraction of these structures are present near the interface region, as shown in Figs. 1 and 2. Other structures such as $\mathrm{Ti}-\mathrm{Ni}, \mathrm{Ni}-\mathrm{C}$, or Ti-C-Ni alloys may also contribute to the strong bond. More detailed studies of the interface structure between $\mathrm{Ni}$ and single crystal TiC underlayer would further elucidate this phenomenon. These different interface structures account for the distribution of electrical resistance of CNFs. In our previous studies, ${ }^{14,15}$ experimentally observed two-terminal resistance of a single Ni-catalyzed CNF of approximately a few micrometers in length has a minimum resistance of $\sim 8.6 \mathrm{k} \Omega$, with the majority of CNFs having resistance around $13.3 \mathrm{k} \Omega$. Thus, the difference is $\sim 4.7 \mathrm{k} \Omega$. By using an existing model ${ }^{16}$ for carbon nanofiber resistivity considering the anisotropy of graphitic planes, we can estimate the resistance for the present CNF configurations. We assume an average CNF diameter of $70 \mathrm{~nm}$, and the thickness of the interface region is estimated to be $100 \mathrm{~nm}$. In addition, the angle between the basal planes of graphite and the CNF axis is estimated to be $90^{\circ}$ and $45^{\circ}$, respectively, for the two dominant interface structures from Figs. 2(c) and 2(d). The computed contact resistances are $10.0 \mathrm{k} \Omega$ for the stacked graphitic layers structure [Fig. 2(c)] and $5.2 \mathrm{k} \Omega$ (much lower) for the cup-shape structure [Fig. $2(\mathrm{~d})$ ], yielding a difference of $4.8 \mathrm{k} \Omega$ between these two interface structures. This result clearly shows that the interaction between the catalyst and the metal underlayer affects the CNF structure near the interface and contributes significantly to contact resistance. In addition, a grain of $\mathrm{TiC}$ might lead to the low resistance as previously reported. ${ }^{17}$ In the present study, $10 \%-20 \%$ of CNFs have a structure with lower resistance and a smaller angle between graphite planes and CNF axis. In order to increase the fraction of suitable interface structures for interconnect applications, the crystal lattice of the metal underlayer should be controlled at the atomic and grain levels before CNF growth.

In conclusion, stacked graphitic layers and cup-shape structures near the CNF-metal interface have been observed using STEM. It has been determined that the interaction between Ni catalyst particles and metal underlayer critically affects the CNF structure during the initial growth stages.
In turn, the CNF-metal contact resistance is dictated by these interface nanostructures. Therefore, understanding the catalyst-metal underlayer interaction is essential for future CNF interconnect development.

The authors are grateful to Kevin Mcilwrath and Konrad Jarausch of Hitachi High-Technologies America for their expert assistance in FIB and STEM experiments, and to Brett A. Cruden of NASA Ames Research Center for helpful discussions.

${ }^{1}$ Y. Chen, Z. L. Wang, J. S. Yin, D. J. Johnson, and R. H. Prince, Chem. Phys. Lett. 272, 178 (1997).

${ }^{2}$ Z. F. Ren, Z. P. Huang, J. W. Xu, J. H. Wang, P. Bush, M. P. Siegal, and P. N. Provencio, Science 282, 1105 (1998).

${ }^{3}$ M. A. Guillorn, A. V. Melechko, V. I. Merkulov, E. D. Ellis, C. L. Britton, M. L. Simpson, D. H. Lowndes, and L. R. Baylor, Appl. Phys. Lett. 79, 3506 (2001).

${ }^{4}$ L. Zhang, A. V. Melechko, V. I. Merkulov, M. A. Guillorn, M. L. Simpson, D. H. Lowndes, and M. J. Doktycz, Appl. Phys. Lett. 81, 135 (2002).

${ }^{5}$ Q. Ngo, B. A. Cruden, A. M. Cassell, G. Sims, M. Meyyappan, J. Li, and C. Y. Yang, Nano Lett. 4, 2403 (2004).

${ }^{6}$ J. Li, R. Stevens, L. Delzeit, H. T. Ng, A. Cassell, J. Han, and M. Meyyappan, Appl. Phys. Lett. 81, 910 (2002).

${ }^{7}$ J. Li, Q. Ye, A. Cassell, H. T. Ng, R. Stevens, J. Han, and M. Meyyappan, Appl. Phys. Lett. 82, 2491 (2003).

${ }^{8}$ J. G. Wen, Z. P. Huang, D. Z. Wang, J. H. Chen, S. X. Yang, Z. F. Ren, J. H. Wang, L. E. Calvet, J. Chen, J. F. Klemic, and M. A. Reed, J. Mater. Res. 16, 3246 (2001).

${ }^{9}$ H. Cui, X. Yang, M. L. Simpson, D. H. Lowndes, and M. Varela, Appl. Phys. Lett. 84, 4077 (2004).

${ }^{10}$ Y. Ominami, Q. Ngo, N. P. Kobayashi, K. Mcilwrath, K. Jarausch, A. M. Cassell, J. Li, and Cary Y. Yang, Ultramicroscopy 106, 597 (2006).

${ }^{11}$ D. Strzeciwilk, Z. Wokulski, and P. Tkacz, Cryst. Res. Technol. 38, 283 (2003).

${ }^{12}$ R. Martel, V. Derycke, C. Lavoie, J. Appenzeller, K. K. Chan, J. Tersoff, and Ph. Avouris, Phys. Rev. Lett. 87, 256805 (2001).

${ }^{13}$ H. Cui, O. Zhou, and B. R. Stoner, J. Appl. Phys. 88, 6072 (2000).

${ }^{14}$ Q. Ngo, A. M. Cassell, A. J. Austin, J. Li, S. Krishnan, M. Meyyappan, and C. Y. Yang, IEEE Electron Device Lett. 27, 221 (2006).

${ }^{15}$ Y. Ominami, Q. Ngo, A. J. Austin, H. Yoong, C. Y. Yang, A. M. Cassell, B. A. Cruden, J. Li, and M. Meyyappan, Appl. Phys. Lett. 87, 233105 (2005).

${ }^{16}$ L. Zhang, D. Austin, V. I. Merkulov, A. V. Meleshko, K. L. Klein, M. A. Guillorn, D. H. Lowndes, and M. L. Simpson, Appl. Phys. Lett. 84, 3972 (2004).

${ }^{17}$ M. Nihei, M. Horibe, A. Kawabata, and Y. Awano, Jpn. J. Appl. Phys., Part 1 43, 1856 (2004). 